\title{
Capsule Endoscopy-Where Are We at 2011 and Where Are We Headed?
}

\author{
Rami Eliakim, M.D. \\ Department of Gastroenterology \& Hepatology Chaim Sheba Medical Center, Tel-Hashomer, \\ Sackler School of Medicine, Tel-Aviv University, Tel-Aviv, Israel
}

Since its introduction over 10 years ago, capsule endoscopy has become an important investigational tool of small bowel, and thereafter of esophageal and colonic pathologies. Over the years, 2nd generation capsules were developed for all three sites, as was a non-video 2 nd generation agile patency capsule to confirm functional patency of the GI tract. Three additional competitive small bowel video capsules have been introduced as well (EndoCapsule, Miro capsule and the OMOM capsule). The present review will describe the available capsules in the market, the procedure itself, present indications and future expectations. (Intest Res 2012;10:235-243)

Key Words: Capsule Endoscopy; Colon Capsule; Small Bowel Capsule; Esophageal Capsule; Colonoscopy; Enteroscopy

\section{INTRODUCTION}

Since its introduction over 10 years ago, ${ }^{1}$ capsule endoscopy has become an important investigational tool of small bowel, and thereafter of esophageal and colonic pathologies. Over the years, 2nd generation capsules were developed for all three sites, as was a non-video 2nd generation agile patency capsule to confirm functional patency of the GI tract (Given Imaging, Yokneam, Israel) (Fig. 1).

Additional competitive small bowel video capsules were developed, all of which are in use in the European Community and some are FDA approved as well- the Japanese EndoCapsule, the Korean Miro capsule and the Chinese OMOM capsule.

Over 1,500 studies have been published looking at the efficacy of various capsules (mainly the small bowel capsule) versus other modalities, at different preparation aiming to improve diagnostic abilities and at technical

Received August 25, 2011. Revised September 6, 2011.

Accepted September 7, 2011.

- Correspondence to : Rami Eliakim, M.D., Head Department of Gastroenterology \& Hepatology Chaim Sheba Medical Center, Tel Hashomer, Israel

Tel: +972-3-530-2679, Fax: +972-3-530-5901

E-Mail: Abraham.eliakim@sheba.health.gov.il aspects.

The present review will describe the available capsules in the market for all three sites, the procedure itself, present indications, contraindications and future expectations. It will mainly focus on the Given Imaging platform as it is the one on which most of the literature was written.

\section{THE SYSTEM}

\section{Small Bowel Capsule Endoscope (SBCE)}

The original PillCam SB1 (Given Imaging, Yoqneam, Israel) video capsule endoscope is a wireless capsule $(11 \times 26 \mathrm{~mm})$ comprised of a light source, lens, CMOS imager, battery and a wireless transmitter. A slippery coating allows easy ingestion and prevents adhesion of contents, while the capsule moves via peristalsis from the mouth to the anus (M2A-the original name of the capsule). The battery provided 8 hours of work in which the capsule photographs 2 images per second ( $>60,000$ images all together), in a 140 degree field of view and 8:1 magnification. The second generation of the small bowel capsule (PillCam SB2, Given Imaging) has been available for a few years. It has a broader angle of view (156 degrees), better optics 

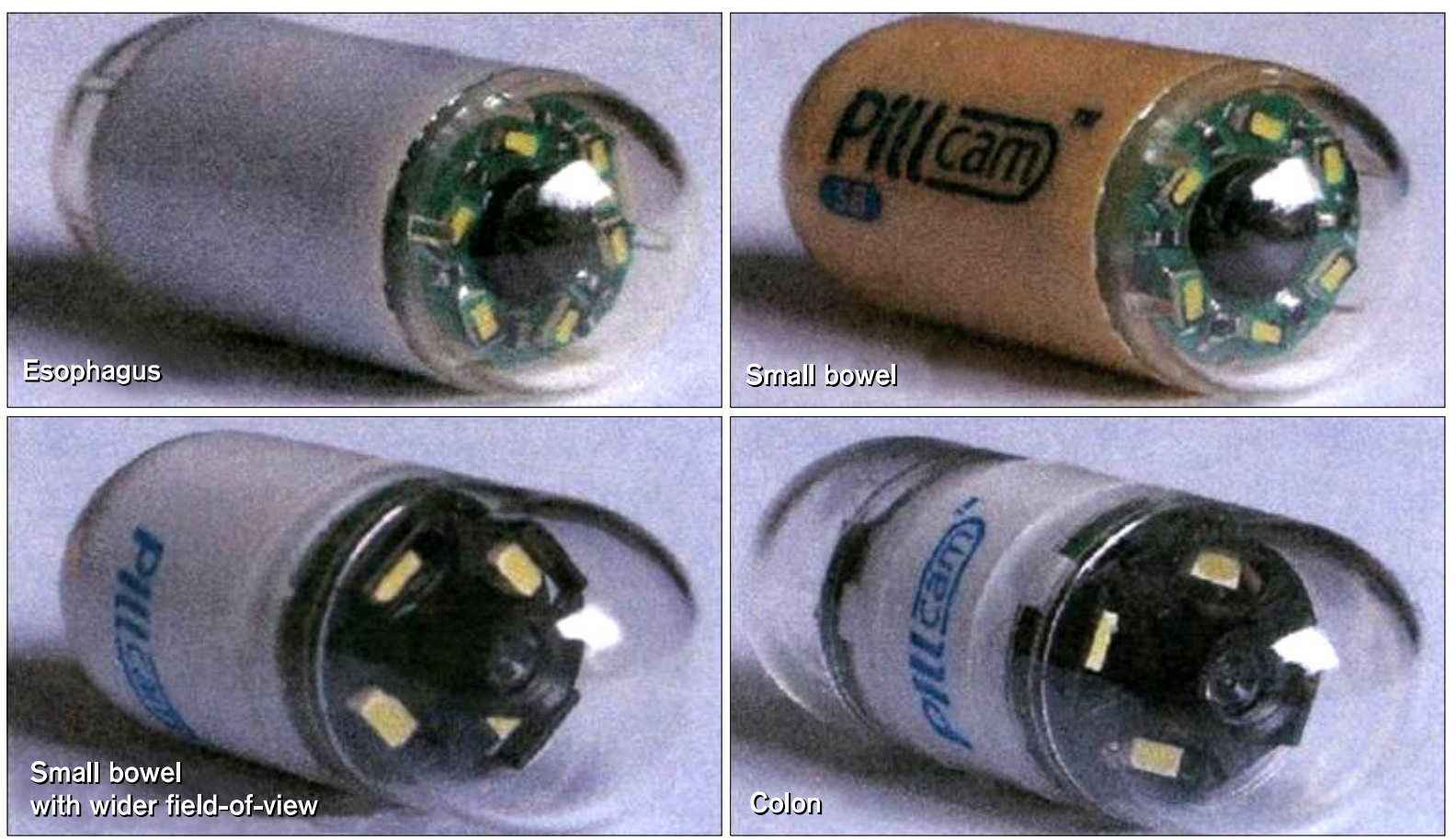

Fig. 1. The PillCam platform of capsule endoscopes (Given Imaging, Yoqneam, Israel).

with an advanced automatic light control, allowing 120 percent better visualization of the small bowel mucosal area. The pictures are transmitted via an eight lead sensor array, attached in a specific fashion on the patient's belly, or a newly developed "no attachments" sensor belt, to a small recorder. The recorder is downloaded into a Reporting and Processing of Images and Data computer workstation (Rapid 7) and seen as a continuous video film. Since its development, support systems have been added. These include a localization system, a blood detector, a double and quadric picture viewer, a quick viewer, single picture adjustment mode, incorporation of the FICE (Fuji Intelligent Color Enhancement, Fuji, Tokyo, Japan) system, an inflammation scoring system (Lewis) and an atlas, all meant to assist the interpreter.

As mentioned, there are additional small bowel capsule systems approved for use in different parts of the world. These include the Olympus EndoCapsule (Olympus, Tokyo, Japan), which was compared head to head to the old generation PillCam SB1 and found to be as good, ${ }^{2}$ the Chinese OMOM pill (Jinshan Science \& Technology, Chongqing, China), ${ }^{3}$ and the Korean
Miro pill (IntroMedic Co., Ltd., Seoul, Korea). ${ }^{4}$ The characteristics and comparison between the capsules are given in Table 1.

\section{Esophageal Capsule Endoscope (ECE)}

The 2 nd generation esophageal capsule is an $11 \times 26$ $\mathrm{mm}$ double headed capsule with a 169 degrees angle of view, capturing 18 frames per second from each side and battery time of $30 \mathrm{~min}$.

\section{Colonic Capsule Endoscope (CCE)}

The 2nd generation colonic capsule, is somewhat bigger than the small bowel capsule $(11 \times 31 \mathrm{~mm})$, is also double header, has a 172 degrees angle of view, with an adjusted frame rate between 2-35 frames per second from each head, depending on the rate of the capsule movement and a battery allowing 10-11 hours of transmission. It has a new data recorder (DR3) that allows crosstalk with the capsule, and has liquid cristal display panel allowing real time visualization as well as the transmission of instructions to the patient, depending 
Table 1. Characteristics of Various Small Bowel Capsule Endoscopes

\begin{tabular}{|c|c|c|c|c|c|}
\hline & PillCam SB1 & PillCam SB2 & EndoCapsule & Miro & OMOM \\
\hline Manufacturer & $\begin{array}{l}\text { Given Imaging, } \\
\text { Yoqneam, Israel }\end{array}$ & $\begin{array}{l}\text { Given Imaging, } \\
\text { Yoqneam, Israel }\end{array}$ & $\begin{array}{l}\text { Olympus Medical Systems } \\
\text { Corporation, Tokyo, Japan }\end{array}$ & $\begin{array}{l}\text { IntroMedic Co., Ltd., } \\
\text { Seoul, Korea }\end{array}$ & $\begin{array}{c}\text { Chongqing } \\
\text { Jinshan Science } \\
\text { \&Technology } \\
\text { (Group) Co., Ltd, } \\
\text { Chongqing, China }\end{array}$ \\
\hline Dimensions (mm) & $26 \times 11$ & $26 \times 11$ & $26 \times 11$ & $10.8 \times 24$ & $13 \times 27.9$ \\
\hline $\begin{array}{l}\text { Field of view } \\
\text { (degree) }\end{array}$ & 140 & 156 & & 150 & 140 \\
\hline $\begin{array}{l}\text { Image storing } \\
\text { speed } \\
\text { (Frames/sec) }\end{array}$ & 2 & 2 & 2 & $2-3$ & $2-15$ \\
\hline $\begin{array}{l}\text { Battery life span } \\
\text { (hr) }\end{array}$ & $7-8$ & $7-8$ & 8 & $9-11$ & 8 \\
\hline $\begin{array}{c}\text { Mode of data } \\
\text { transmission }\end{array}$ & Radiofrequency & Radiofrequency & Radiofrequency & $\begin{array}{c}\text { Electrical field } \\
\text { propagation }\end{array}$ & Radiofrequency \\
\hline
\end{tabular}

Reprinted with permission from Wolters Kluwer Health (Curr Opin Gastroenterol 2010;26:129-133).

on the capsule's location in the intestine. A polyp size estimator and the use of the FICE technique have been integrated into its new Rapid 7 working station.

\section{THE PROCEDURE}

\section{SBCE}

For the patient, this is an easy, safe, noninvasive and ambulatory procedure. The patient is on clear liquids the day prior to the procedure and swallows the capsule with water after a 12 hour fast. The patient can drink clear fluids, 2 hours after capsule ingestion and eat a light lunch after 4 hours. During the procedure he is free to do his daily activities. Theoretically, the patient can be connected at home and disconnected at work, allowing a regular daily schedule.

Some investigators have suggested the addition of a bowel preparation in order to improve the rate of complete small bowel endoscopy and visualization of distal small bowel. A meta-analysis looking at the efficiency of bowel preparation concluded that preparation improves the quality of visualization, but has no effect on transit times or percentage of capsules reaching the cecum. There was no agreement whether there was an effect on the diagnostic yield. ${ }^{5}$ Two prospective studies have found no advantage for bowel preparation with oral sodium phosphate, or for the use of bowel purgatives or/and prokinetic agents. ${ }^{6,7}$ Some authors have used Simethicone to prevent excess bubbles in small bowel. Incomplete small bowel transit while doing the examination is about $20 \%$. Previous small bowel surgery, hospitalization, moderate or poor bowel cleansing and gastric transit time longer than 45 minutes are all independent risk factors for incomplete SBCE procedures. ${ }^{8}$

\section{2. $E C E$}

The swallowing technique for the esophageal capsule is somewhat different than for the small bowel. After a 3 hour fast the patient drinks $100 \mathrm{~mL}$ of water in order to clean the esophagus from saliva and debris, lies in the left later decubitis position and with a sip of $15 \mathrm{~mL}$ water swallows the capsule, followed by $15 \mathrm{~mL}$ sips every 30 seconds until the capsule, seen by real time viewing, enters the stomach. ${ }^{9}$ The addition of simethicone was of no value in our hands.

\section{CCE}

The preparation for the colon capsule procedure need to take into account that the bowel has to be very clean and that the capsule needs to reach the anus while photographing, i.e., within 11 hours after being swallowed. The preparation is quite similar to that of regular 
colonoscopy up to the capsule's swallow- i.e., a day prior to the procedure the patient is on clear liquid diet. On the evening prior to the procedure he drinks 2 liters of PEG solution. Early morning, on procedure day, he drinks another 2 liters of PEG and an hour later ingests the capsule. Once the capsule has entered the small bowel the patient will drink a boost of either Sodium Phosphate $(30 \mathrm{~mL})$, or a sachet of PicoLax followed by a liter of water in order to propel the pill to the colon and allow its exit through the anus while still photographing. Another smaller $(15 \mathrm{~mL})$ boost, or another sachet of PicoLax will be given depending on the capsule's location in the intestine..$^{10,11}$

\section{INDICATIONS FOR USE}

\section{SBCE (Table 2)}

Obscure GI bleeding (OGIB): The primary indication for which the FDA approved SBCE in 2001 was OGIB. ${ }^{12}$ Since then many reports have shown a statistically significant increased diagnostic yield of SBCE over push enteroscopy and other modalities in the range between $39-90 \%^{13,14}$ and a similar diagnostic yield to balloon assisted enteroscopy. ${ }^{15}$ It has been shown that the closer SBCE is done to the bleeding episode, the higher the diagnostic yield. ${ }^{14}$ The sensitivity of SBCE ranges between $89-92 \%$, and the specificity is around $95 \%$. The new algorithm for OGIB suggests SBCE as the initial investigation after a negative upper and lower

Table 2. Indication and Contraindications for the Use of Capsule Endoscopy

\begin{tabular}{l}
\hline Indications \\
1. Occult gastrointestinal bleeding \\
2. Suspected Crohn's disease \\
3. Suspected small bowel tumor \\
4. Surveillance of inherited polyposis syndromes \\
5. Evaluation of abnormal small bowel imaging \\
6. Evaluation of drug induced small bowel injury \\
7. Partially responsive celiac disease \\
Contraindications \\
1. Dysphagia or any swallowing disorder \\
2. Non compliance \\
3. Previous history/suspected small bowel obstruction \\
4. Cardiac devices-pacemaker/defibrillator (relative) \\
5. Major abdominal surgery <6 months (relative) \\
6. Pregnancy
\end{tabular}

endoscopy, followed by push, double balloon, or intra operative enteroscopy as therapeutic procedures. A negative capsule endoscopy study in patients with obscure bleeding is associated with low rate of recurrent bleeding in the long term, making it reasonable to use. ${ }^{16}$

Crohn's disease: Studies evaluating the use of SBCE in suspected Crohn's disease, suggested it had a higher diagnostic yield compared to other modalities. ${ }^{17} \mathrm{~A}$ meta-analysis reviewing prospective comparative studies comparing SBCE to other modalities, found SBCE to have a better incremental yield ranging between $15-44 \%$ compared to other modalities. This was true for both known and suspected Crohn's disease. ${ }^{18}$ Recently, an the Organization Mondial d'Endoscopie and the European Crohn's and Colitis Organisation consensus on the role of SBCE in the management of patients with IBD stated that SBCE is able to identify lesions compatible with Crohn's disease in some patients in whom conventional endoscopic and radiographic imaging modalities have been non-diagnostic. ${ }^{19}$ It was better than small bowel follow through or enteroclysis, and a normal capsule study has a high negative predictive value for active small bowel Crohn's. ${ }^{19}$

In patients with known Crohn's, SBCE may alter disease management by assessing mucosal healing after medical therapy. The role of SBCE in assessing early postoperative recurrence compared to Ileo-colonoscopy is contradictory. ${ }^{20,21} \mathrm{SBCE}$ detected more lesions in the proximal small bowel in both studies in these patients. SBCE was found to be clinically useful for categorizing patients with indeterminate colitis, although negative SBCE study did not exclude further diagnosis of Crohn's. ${ }^{22}$

Patients with a few aphthous lesions in the small bowel on SBCE may create a problem, as other causes such as NSAIDs can macroscopically look similar. Thus it is advised to abstain from use of NSAIDs for at least 1 month prior to capsule examination.

Small bowel tumors: SBCE has more than doubled the rate of diagnosing small bowel tumors from around $3 \%$ to $6-9 \%$. Most of the tumors are found in patients undergoing SBCE for OGIB, and $50-60 \%$ is of malignant nature. ${ }^{23-25}$ As the outcome of small bowel tumors depends on their early diagnosis, a more liberal use of SBCE for GI symptoms might lead to improved 
management and survival of these patients, but this waits to be proven.

Inherited polyposis syndromes: SBCE can be used to survey small bowel polyps in patients with polyposis syndromes. SBCE has a better diagnostic capability compared to barium follow-through in patients with Peutz-Jeghers syndrome. ${ }^{26,27}$ The duodenum is a potential pitfall as the capsule passes it very fast and thus may give false negative results. ${ }^{28}$ Size estimation is another problem. SBCE detected less polyps and underestimate the size of large polyps compared to enteroscopy. ${ }^{29}$ Coupling of SBCE with double balloon enteroscopy and polypectomy, it may offer an ideal method of follow up and treatment of these patients, possibly avoiding surgery. ${ }^{29}$

Celiac disease: SBCE provides high-resolution magnified view of the mucosa, easily identifying the endoscopic changes found in celiac such as scalloping, mosaic pattern, flat mucosa, loss of folds and nodularity. It can also provide information on the distribution of the disease in specific individuals, be a surveillance tool in partial or non-responders, or for initial diagnosis in patients with positive serology who refuse conventional endoscopy. SBCE was shown to be very sensitive in patients with proven celiac disease, ${ }^{30}$ and as a prognostic tool in patients with proven celiac who develop symptoms and possibly in the future as an initial diagnostic test for confirming atrophy in sero- positive patients. $^{31}$

Monitoring the effects or side effects of drugs: SBCE can be used to monitor deleterious effects of drugs such as NSAIDs on small bowel mucosa. SBCE clearly demonstrated NSAIDs induced small bowel damage by both COX1 and COX2 antagonists. Lesions included erythema, erosions, small ulcerations and web like strictures. ${ }^{32}$ SBCE can be used to monitor The effect of drugs used to protect against NSAIDS induced small bowel injury, ${ }^{33}$ to monitor the small bowel mucosa condition in transplant patients, in the management of graft versus host disease and possibly to monitor mucosal healing of small bowel Crohn's disease after various medical treatments. 34,35

Motility: Progress has been made in the evaluation of small bowel motility using SBCE. Endoluminal image analysis by means of computer vision and machine- learning techniques has been shown to constitute a reliable, non invasive and automated diagnostic test of intestinal motor disorders. ${ }^{36}$ Another "physiological" pill- the Smart-Pill has been developed. This is an $11 \times 26 \mathrm{~mm}$ pill with $\mathrm{pH}$, temperature and pressure sensors, without a camera. The pill is FDA approval for gastric transit and characterization of constipation.

\section{ECE}

1) Surveillance of varices in patients with chronic liver disease.

2) Surveillance of Barrett's esophagus in patients with long standing reflux disease.

3) Diagnosis of esophagitis in patients unwilling to undergo standard endoscopy.

\section{CCE}

1) Incomplete colonoscopy.

2) Examination of symptomatic patients unwilling to undergo regular colonoscopy.

3) Surveillance of individuals unwilling to undergo regular colonoscopy.

Therefore, we have made a long, fantastic journey since the first small bowel capsule was introduced 10-11 years ago. However, with the "food" comes more appetite and we are looking forward to further develop the next generations of capsule and have great expectations (Table 3$)^{37}$

Table 3. Future Expectations from the Wireless Capsule Endoscope

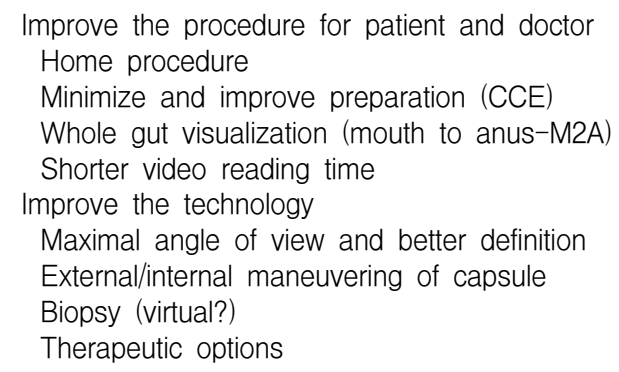

CCE, colonic capsule endoscope. 


\section{*Improve the procedure for patient and doctor}

Home procedure: The system should be capable of home use. This is especially relevant for CCE. A kit containing the capsule, sensors and data recorder, will allow the patient to perform the entire procedure at home, possibly as a weekend procedure avoiding the need to take time off work. The already available new data recorder can alert the patient of each and every move of the capsule and give actual instruction to take the boosts as needed. If necessary, on-line visualization can be performed via wireless field.

Preparation: For SBCE future studies will answer whether we need any preparation aside from 12 hours fast, and whether it will increase our diagnostic yield. If so we need this preparation to be friendly, possibly a 'pill cleanser' instead of large volume liquid solutions. For CCE, we should produce easier preparations, which will replace the use of 4 liter PEG solution with some 'pill cleansers' that are enteric coated allowing them to open and start their effect in distal small bowel, as the basic cleansing materials of the colonic content. We should produce safer materials than Sodium Phosphate or PicoLax that will help propel the capsule faster to the colon. Even better, smart visualization through colonic content should be developed to minimize or preclude bowel preparation at all.

Whole gut visualization: Capsule endoscopy can provide a comprehensive examination and diagnosis of pathologies of the entire gut with single minimally invasive procedure, just as the original inventors dreamt. The idea is to use a capsule similar to CCE that has two domes and an adaptive frame rate and thus can nicely visualize the esophagus. One can use an external maneuvering device to control the capsule movement, examine the stomach and duodenum and then move it faster through the small bowel which will be visualized, followed by the colon without extra burden to the patient. This would be a perfect screening tool for patients with iron deficiency anemia or suspected IBD.

Short video reading time: Currently the longest reading time is of CCE video which is approximately 40-60 minutes. Future system should allow significantly shorter reading time, possibly by automated detection and alerts to the person interpreting the video of existing pathologies, be it polyps, anterio-venous malformations, inflammation etc. (i.e., "Pathology indicator"). This will definitely shorten CCE and possibly SBCE reading times.

\section{*Improve technology}

Maximal angle of view and better definition: An angle of view of 180 degrees from each dome will improve visualization and help not to miss pathologies. The conventional small bowel capsules have an angle of view ranging between 140-154 degrees and these needs to be enlarged. The 2nd generation CCE has a 172 degrees angle of view from each side, allowing almost 380 degrees view of the bowel wall. A Japanese company described a small $23 \times 9 \mathrm{~mm}$ capsule endoscope in its website, the Sayaka endoscope (Sayaka, Nagano, Japan), which maps the inner gut while rotating through the digestive system, taking 30 pictures per second with a 360 degrees angle of view (Fig. 2). ${ }^{38}$ To the best of our knowledge, no human studies have been conducted with this capsule which is described on the web for over than five years. The future capsule endoscope will probably provide higher resolution (high definition) photos and conversion of the light to specific wave length (like the FICE system).

External/internal maneuvering of capsule: A more

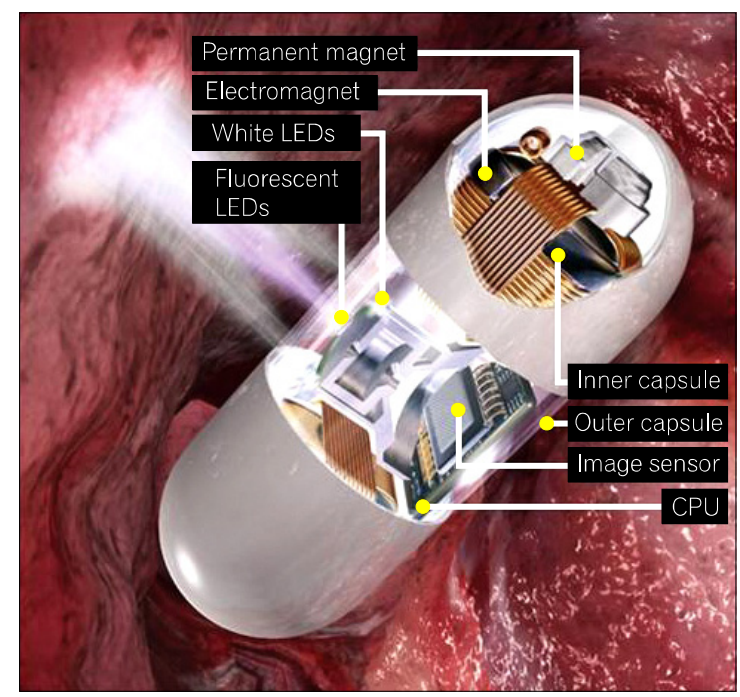

Fig. 2. The Sayaka endoscope (Sayaka, Nagano, Japan). Reprinted with permission from Elsevier (Gastroenterology 2010;139:1468-1471). 
active capsule requires adding either external or internal appendages that will allow it to propel through the GI tract. Swain and colleagues, have conducted the first human volunteer study in which they transformed a wireless colon based capsule (Given Imaging) to contain a stack of neodymium-iron-boron magnets in one of its domes, allowing it to be manipulated with an external hand held magnet ('joy stick'), for ten minutes in the esophagus and stomach. ${ }^{39,40}$ Olympus and Siemens have introduced a similar concept to the Japanese pill as well. ${ }^{41}$ Another approach is to add to the capsule parts such as paddles/propellers that will start operating upon demand at various parts of the digestive tract. A third approach would be a combination of the two mentioned above- a magnet for the upper tract and an internal device for the small/large bowel. An Italian group has tested such a device in pigs. One can easily foresee what can be done with such devices in the colon or entire gut, allowing a very thorough examination of the gut and colon.

Biopsy: biopsy capabilities can identify risky lesions, optimize referral to therapeutic treatment and improve patient management. This is true for the small bowel and probably even more to polyps of various sizes in the colon. In addition to the FICE feature already included with the capsule reading software, one can speculate on using other single or multimodalities such as narrow band imaging, oxygen demands and spectral analysis together to improve visualization, pathology detection and patient management. In Vivo molecular diagnostics might be implemented as well. One may inject or give fluorescent labeled antibodies/bids which will bind to unique antigens/proteins on tissue and later on will be detected by the capsule via a specific fluorescence light detector. Similarly, these antibodies can detect specific antigens in luminal secretions and the complex attached/detected by the capsule using reflection or fluorescence.

Virtual biopsy has been discussed extensively in a former review by Sharma. ${ }^{42}$ At least two such devices exist and are being tested in animals. The Korean rotational micro biopsy capsule device, containing a trigger part and a biopsy part, and the versatile endoscopy capsule for GI tumor recognition and therapy (VECTOR) capsule, part of the European Union effort to develop capsules with recognition abilities, anchoring devices, virtual biopsies and even drug delivery. These technologies will certainly advance us huge steps forward in our ability to give precise diagnosis and treatment.

Therapeutic options: Phillips, has launched a drug delivery pill (intelligent pill-I-Pill, Amsterdam, Netherlands) which incorporates a microprocessor, batter, $\mathrm{pH}$ sensor, temperature sensor, a radiofrequency transceiver, a fluid pump, and a drug reservoir, all in a $11 \times 26$ $\mathrm{mm}$ pill, which will open and deliver the drug in the designated area in the bowel allowing targeted therapy to inflammatory sites, AVM's and tumors (Fig. 3).

Thus, in the future we will have two kinds of capsules-a diagnostic capsule applying the improve-
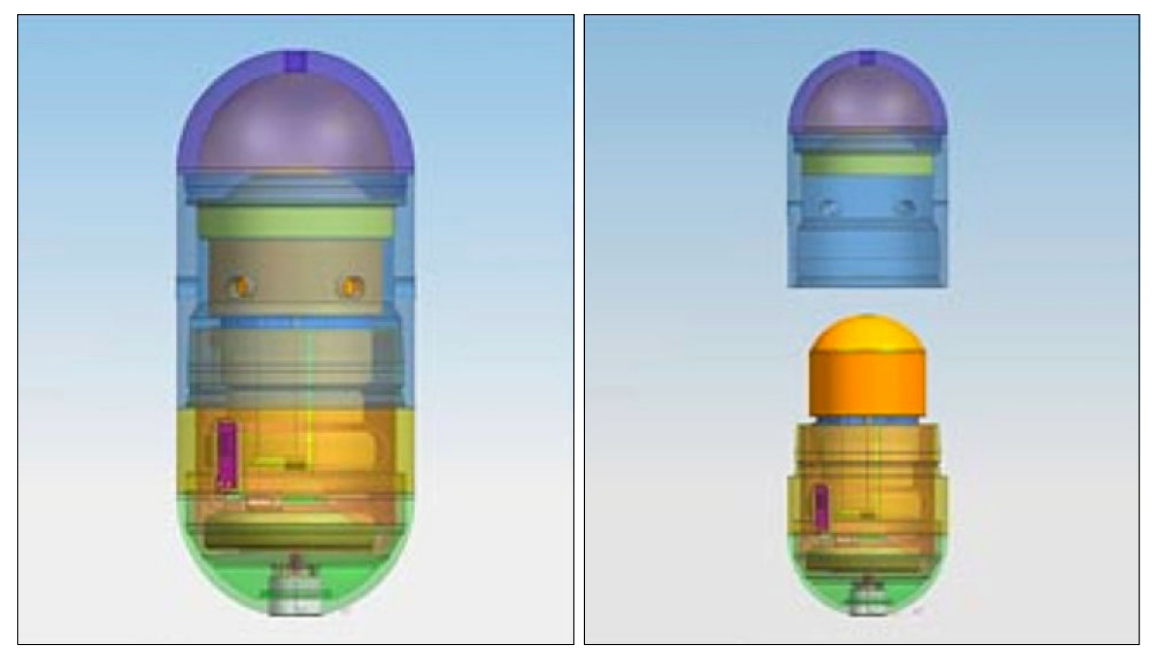

Fig. 3. The Phillips intelligent pill (I-Pill). This $11 \times 26-\mathrm{mm}$ capsule contains a microprocessor, battery, $\mathrm{pH}$ sensor, temperature sensor, REF transceiver, fluid pump, and drug reservoir. Reprinted with permission from the Elsevier (Gastroenterology 2010;139:14681471). 
ments in image quality, angle of view, pathology detection, virtual biopsies, and advances in software and communication, that will cover all the GI tract from mouth to anus. A 2nd capsule-a therapeutic capsule will apply the advances of the maneuvering abilities and anchoring abilities as well as drug delivery abilities and possibly other options for mechanical therapy.

\section{REFERENCES}

1. Iddan G, Meron G, Glukhovsky A, Swain P. Wireless capsule endoscopy. Nature 2000;405:417.

2. Cave DR, Fleischer DE, Leighton JA, et al. A multicenter randomized comparison of the Endocapsule and the Pillcam SB. Gastrointest Endosc 2008;68:487-494.

3. Liao Z, Gao R, Li F, et al. Fields of applications, diagnostic yields and findings of OMOM capsule endoscopy in 2400 Chinese patients. World J Gastroenterol 2010;16:2669-2676.

4. Bang S, Park JY, Jeong S, et al. First clinical trial of the "MiRo" capsule endoscope by using a novel transmission technology: electric-field propagation. Gastrointest Endosc 2009;69:253-259.

5. Niv Y. Efficiency of bowel preparation for capsule endoscopy examination: a meta-analysis. World J Gastroenterol 2008;14: 1313-1317.

6. Lapalus MG, Ben Soussan E, Saurin JC, et al; Société Française d'Endoscopie Digestive. Capsule endoscopy and bowel preparation with oral sodium phosphate: a prospective randomized controlled trial. Gastrointest Endosc 2008;67:1091-1096.

7. Postgate A, Tekkis P, Patterson N, Fitzpatrick A, Bassett P, Fraser C. Are bowel purgatives and prokinetics useful for smallbowel capsule endoscopy? A prospective randomized controlled study. Gastrointest Endosc 2009;69:1120-1128.

8. Westerhof J, Weersma RK, Koornstra JJ. Risk factors for incomplete small-bowel capsule endoscopy. Gastrointest Endosc 2009;69:74-80

9. Gralnek IM, Rabinovitz R, Afik D, Eliakim R. A simplified ingestion procedure for esophageal capsule endoscopy: initial evaluation in healthy volunteers. Endoscopy 2006;38:913-918.

10. Eliakim R, Yassin K, Niv Y, et al. Prospective multicenter performance evaluation of the second-generation colon capsule compared with colonoscopy. Endoscopy 2009;41:1026-1031.

11. Spada C, Hassan C, Munoz-Navas M, et al. Second-generation colon capsule endoscopy compared with colonoscopy. Gastrointest Endosc 2011;74:581-589.

12. Lewis BS, Swain P. Capsule endoscopy in the evaluation of patients with suspected small intestinal bleeding: Results of a pilot study. Gastrointest Endosc 2002;56:349-353.

13. Triester SL, Leighton JA, Leontiadis GI, et al. A meta-analysis of the yield of capsule endoscopy compared to other diagnostic modalities in patients with obscure gastrointestinal bleeding. Am J Gastroenterol 2005;100:2407-2418.

14. Pennazio M, Santucci R, Rondonotti E, et al. Outcome of patients with obscure gastrointestinal bleeding after capsule endoscopy: report of 100 consecutive cases. Gastroenterology 2004;126:643-653.
15. Pasha SF, Leighton JA, Das A, et al. Double-balloon enteroscopy and capsule endoscopy have comparable diagnostic yield in small-bowel disease: a meta-analysis. Clin Gastroenterol Hepatol 2008;6:671-676.

16. Macdonald J, Porter V, McNamara D. Negative capsule endoscopy in patients with obscure GI bleeding predicts low rebleeding rates. Gastrointest Endosc 2008;68:1122-1127.

17. Eliakim R, Suissa A, Yassin K, Katz D, Fischer D. Wireless capsule video endoscopy compared to barium follow-through and computerised tomography in patients with suspected Crohn's disease--final report. Dig Liver Dis 2004;36:519-522.

18. Dionisio PM, Gurudu SR, Leighton JA, et al. Capsule endoscopy has a significantly higher diagnostic yield in patients with suspected and established small-bowel Crohn's disease: a meta-analysis. Am J Gastroenterol 2010;105:1240-1248.

19. Bourreille A, Ignjatovic A, Aabakken L, et al; World Organisation of Digestive Endoscopy (OMED) and the European Crohn's and Colitis Organisation (ECCO). Role of small-bowel endoscopy in the management of patients with inflammatory bowel disease: an international OMED-ECCO consensus. Endoscopy 2009;41:618-637.

20. Bourreille A, Jarry M, D'Halluin PN, et al. Wireless capsule endoscopy versus ileocolonoscopy for the diagnosis of postoperative recurrence of Crohn's disease: a prospective study. Gut 2006;55:978-983

21. Pons Beltrán V, Nos P, Bastida G, et al. Evaluation of postsurgical recurrence in Crohn's disease: a new indication for capsule endoscopy? Gastrointest Endosc 2007;66:533-540.

22. Maunoury V, Savoye G, Bourreille A, et al. Value of wireless capsule endoscopy in patients with indeterminate colitis (inflammatory bowel disease type unclassified). Inflamm Bowel Dis 2007;13:152-155

23. Bailey AA, Debinski HS, Appleyard MN, et al. Diagnosis and outcome of small bowel tumors found by capsule endoscopy: a three-center Australian experience. Am J Gastroenterol 2006; 101:2237-2243

24. Schwartz GD, Barkin JS. Small-bowel tumors detected by wireless capsule endoscopy. Dig Dis Sci 2007;52:1026-1030.

25. Cobrin GM, Pittman RH, Lewis BS. Increased diagnostic yield of small bowel tumors with capsule endoscopy. Cancer 2006; 107:22-27.

26. Brown G, Fraser C, Schofield G, et al. Video capsule endoscopy in peutz-jeghers syndrome: a blinded comparison with barium follow-through for detection of small-bowel polyps. Endoscopy 2006:38:385-390.

27. Iaquinto G, Fornasarig M, Quaia M, et al. Capsule endoscopy is useful and safe for small-bowel surveillance in familial adenomatous polyposis. Gastrointest Endoscop 2008;67:61-67.

28. Clarke JO, Giday SA, Magno P, et al. How good is capsule endoscopy for detection of periampullary lesions? Results of a tertiary-referral center. Gastrointest Endosc 2008;68:267-272.

29. Ohmiya N, Taguchi A, Shirai K, et al. Endoscopic resection of Peutz-Jeghers polyps throughout the small intestine at doubleballoon enteroscopy without laparotomy. Gastrointest Endosc 2005;61:140-147.

30. Rondonotti E, Spada C, Cave D, et al. Video capsule enteroscopy in the diagnosis of celiac disease: a multicenter study. Am J Gastroenterol 2007:102:1624-1631. 
31. Cellier C, Green PH, Collin P, Murray J; ICCE. ICCE consensus for celiac disease. Endoscopy 2005;37:1055-1059.

32. Graham DY, Opekun AR, Willingham FF, Qureshi WA. Visible small-intestinal mucosal injury in chronic NSAID users. Clin Gastroenterol Hepatol 2005;3:55-59.

33. Fujimori S, Seo T, Gudis K, et al. Prevention of nonsteroidal anti-inflammatory drug-induced small-intestinal injury by prostaglandin: a pilot randomized controlled trial evaluated by capsule endoscopy. Gastrointest Endosc 2009;69:1339-1346.

34. Neumann S, Schoppmeyer K, Lange T, et al. Wireless capsule endoscopy for diagnosis of acute intestinal graft-versus-host disease. Gastrointest Endosc 2007;65:403-409.

35. Yakoub-Agha I, Maunoury V, Wacrenier A, et al. Impact of small bowel exploration using video-capsule endoscopy in the management of acute gastrointestinal graft-versus-Host disease. Transplantation 2004;78:1697-1701.

36. Malagelada C, De Iorio F, Azpiroz F, et al. New insight into intestinal motor function via noninvasive endoluminal image analysis. Gastroenterology 2008;135:1155-1162.
37. Eliakim R. Video capsule colonoscopy: where will we be in 2015? Gastroenterology 2010;139:1468-1471.

38. RF System Lab, Sayaka [homepage on the Internet]. Nagano, Japan: RF Co., Ltd [cited 2011]. Available from: http://www. rfamerica.com/sayaka

39. Swain P, Toor A, Volke F, et al. Remote magnetic manipulation of a wireless capsule endoscope in the esophagus and stomach of humans (with videos). Gastrointest Endosc 2010;71:12901293.

40 Keller J, Fibbe C, Volke F, et al. Remote magnetic control of a wireless capsule endoscope in the esophagus is safe and feasible: results of a randomized, clinical trial in healthy volunteers. Gastrointest Endosc 2010;72:941-946.

41. Rey JF, Ogata H, Hosoe N, et al. Feasibility of stomach exploration with a guided capsule endoscope. Endoscopy 2010; 42:541-545.

42. Sharma VK. The future is wireless: advances in wireless diagnostic and therapeutic technologies in gastroenterology. Gastroenterology 2009;137:434-439. 